\title{
System Architecture of a Student Relationship Management System using Internet of Things to collect Digital Footprint of Higher Education Institutions
}

\author{
https://doi.org/10.3991/ijet.v14i23.11066 \\ Nualsri Songsom ${ }^{(凶)}$ \\ Suan Dusit University, Bangkok, Thailand \\ nuasri_sonedusit.ac.th \\ Prachyanun Nilsook and Panita Wannapiroon \\ King Mongkut's University of Technology North Bangkok, Bangkok, Thailand \\ Chun Che Fung and Kok Wai Wong \\ Murdoch University, Perth, Western Australia
}

\begin{abstract}
Effective system development to support higher education institutions is important. There are two steps in developing a good system and they are system architecture analysis and design. The first task of this research is to design the use case diagrams, system overview and the system architecture. The second is to evaluate the system architecture of a proposed Student Relationship Management (SRM) system using Internet of Things (IoT) to collect digital footprint of higher education institutions. The outcome of this research include the system architecture of the proposed student relationship management system (SRMS)-IoT consists of six main parts: 1) service stations, 2) system identification, 3) system integration API, 4) SRM internal system, 5) report analytic and 6) web server and database server. Evaluation of the results shows an overall appropriateness at a very high level: the overall appropriateness of usability result was also at a very high level, which shows that this research is appropriate to be used as a guideline for further system development to support student services, and to promote learning and analysis of student behavior in higher education institutions.
\end{abstract}

Keywords—System Architecture, Student Relationship Management, Internet of Things, Digital Footprint

\section{Introduction}

It is important that higher education institutions promote students' academic development and create appropriate learning activities. In general, service stations in higher educational institutions such as libraries, student affairs facilities, first aid room, canteens etc., are important for student activities because they enhance students' experience in the campus. Furthermore, studies have shown good student services and sup- 
ports help to promote students' learning [1-4]. At present, there is a focus on providing services support using advanced technologies in order to assist the management [5-6]. For the students to access or receive the services efficiently, higher educational institutions should aim to communicate or interact with students at any time [7]. Currently, there are a lot of advanced technologies that could be adapted to the context of higher education institutions for maximum benefits.

Education is multi-faceted. It includes teaching and learning, and follow-up of students in and out of the classrooms or the higher education institutions. Education should also provide learning development, security, monitoring of services received, classroom management, and other information which are useful for students. Such services should be made available from the higher education institutions comprehensively [8-9]. The Bluetooth beacons is an example of the advanced technology under the spectrum of "Internet of Things" (IoT). IoT can work effectively, and they are capable to create interactions and connections between people, objects and space over distances, which is important to help the development and enhancement of student learning [10]. When using IoT, a digital footprint automatically occurs and such information within the higher educational institutions could be used to support the Management or relevant units in order to be used for further benefits [11 - 12]. Information such as Student Behavior Analysis can be used as an effective reference of higher education institutions for the planning, development and management of student activities. [19]

Songsom, Nilsook and Wannapiroon (2019) presented the concept and elements of a Student Relationship Management System (SRMS) using IoT to collect digital footprint within higher education institutions. The design has five modules:

- The Identify module which concerns with authentication and identification at the students service access points

- The Alert module which informs students with messages after entering the service point

- The Tracking module which stores the tracking data of students

- The Student Relationship Management (SRM) module which stores service information for providing services to the students

- The Analytic module which analyzes the reports from information that is stored from other parts of the system. For efficiency and accuracy, the modules are expected to work together in real time [13]. 


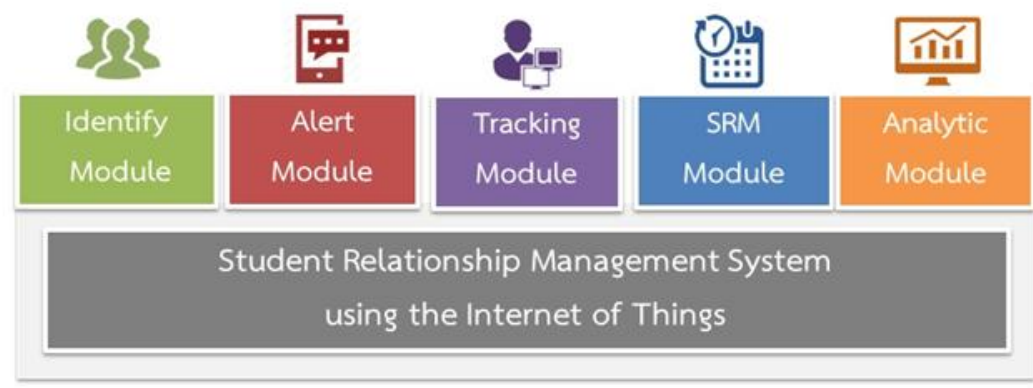

Fig. 1. The element diagram of the SRMS using IoT to collect digital footprint of higher education institutions. [13]

System architecture is important as it allows the developers to understand the factors and the environment of the system [16].

The background outlined and the significance of this research prompted the researchers to focus on the concept of system development including use case diagrams, overview of the system and system architecture design of the SRMS using IoT to collect digital footprint of higher education institutions.

\section{Literature Review}

\subsection{System Architecture}

System architecture is a process of structured problem solving that meets the technical requirements and all work operations. In general, it must be effective with respect to safety and management capabilities. It also has to be effective in the system maintenance, as it is related to the overall system operation. Good system architecture design must be flexible and supports work that may change over time. It takes into account of both hardware and software, as well as various operational situations and requirements from users. [14]

There are many research related system architecture designs to benefit students. For example, the analysis and design of a mobile augmented book system architecture, for learning inside and outside of the classroom, helped to improve the quality and benefits of learning using mobile devices [15]. The system architecture that is presented here has three layers: a Presentation layer, an Application logic layer and a Data layer. Each layer has an internal component that works in a systematic way [15]. It is important to use Information and Communication Technology (ICT) for students so that they are satisfied with the activities that are complementary to learning. Previous work has also designed the architecture of a portfolio system to monitor activities using IoT in digital universities with the goal of automatically storing the number of hours of student participation in activities. The system consists of three main components: an Application layer, which is used to interface with users; a Network layer, which connects to the network of mobile devices, Wi-Fi and Internet signal; and final- 
ly, a Sensor layer, which comprises the hardware such as receiver and transmitter installed at the event spots [16].

\subsection{Student Relationship Management (SRM)}

Student relationship management is a concept that creates good relationships between the higher education institutions and the students, who are recognized as an important part of the institutions. At present, the importance and satisfaction of customers has been changed from general strategies to become rules that are required for business competition, and this concept is now applied to educational institutions. The term SRM, is now being recognize as an important aspect for educational institutions. Universities are highly competitive and they need to improve their operational efficiency. With respect to education services and SRM concepts, the concepts and principles derived from relationship management with customers becomes important because they are in possession of information such as students' records, academic results or activities within the university. Such information can be leveraged to improve satisfaction and to provide appropriate services to the students [5-6]. Satisfied students happy with sufficient and thorough student services, both inside and outside the classroom, reflect good and effective management of the higher education institutions [2].

\subsection{Internet of Things (IoT)}

The IoT is a concept that connects objects by embedding electronic devices, software and sensors to enable interconnection, communication and exchange of information. The key fuctions of IoT are:

- Identification

- Sensing

- Communication

- Computation

- Services

- Semantics [8]

Development of systems to monitor student activities in schools using Radio frequency identification (RFID) IoT will assist to create safe measures reduce the burden of school administration. Technology may help tracking of students as regard to their movement and such information could be of use to school administrators, parents, teachers and bus drivers in real time for scheduling and safety reasons [9]. This also aligns with the growing popularity of smart phones and personal tablet devices due to their easy access to wireless network. This has led research to examine the benefits from these technologies such as Bluetooth beacons [10]. 


\subsection{Digital Footprint}

Digital footprint is data that occurs after the user has accessed the Internet. Increased Internet use over time has created a lot of digital footprint. In addition, large social network organizations have already investigated in-depth studies concerning personal details and movements. For example, Facebook is capable to predict and summarize the impact of those results and studied in the extent concerning the privacy of the data owner [12 - 13]. Fan, Li, Liu and Chen (2015) studied the correlation from behavior analysis of students within higher educational institutions including book loans, consumption behavior, movement trajectory and academic achievements these results are useful for higher education institutions in order to plan the development of services and the learning of students [19].

\section{$3 \quad$ Research Objectives}

The research objectives of this study are listed as follows:

- To design the use case diagram of the SRMS using IoT to collect digital footprint of higher education institutions

- To design the overview system of the SRMS using IoT to collect digital footprint of higher education institutions

- To design the system architecture of the SRMS using IoT to collect digital footprint of higher education institutions

- To evaluate the system architecture of the SRMS using IoT to collect digital footprint of higher education institutions

\section{$4 \quad$ Research Methodology}

The research on the study and design of the system architecture of the SRMS using the IoT to collect digital footprint of higher education institutions was conducted by reviewing documents, literature and related research. The research was conducted in four phases as follows:

- Phase 1: Design of the use case diagram of the SRMS using IoT to collect digital footprint of higher education institutions.

- Phase 2: Design of the overview system of the SRMS using IoT to collect digital footprint of higher education institutions.

- Phase 3: Design of the system architecture of the SRMS using IoT to collect digital footprint of higher education institutions.

The research instruments for this phase were:

- Development of the overview system of the SRMS using IoT to collect digital footprint of higher education institutions 
- Development of the system architecture of the SRMS using IoT to collect digital footprint of higher education institutions

- Development of the evaluation metrics of the system architecture designed

- Phase 4: The evaluation of the system architecture of the SRMS using IoT to collect digital footprint of higher education institutions by ten experts who have experience in the field of system architecture, SRM, IoT and ICT using the purposive method.

\section{$5 \quad$ Results}

- Phase 1: Design of the use case diagram of the SRMS using IoT to collect digital footprint of higher education institutions.

The design of the use case diagram of the SRMS using IoT to collect digital footprint of higher education institutions is shown in Fig. 2.

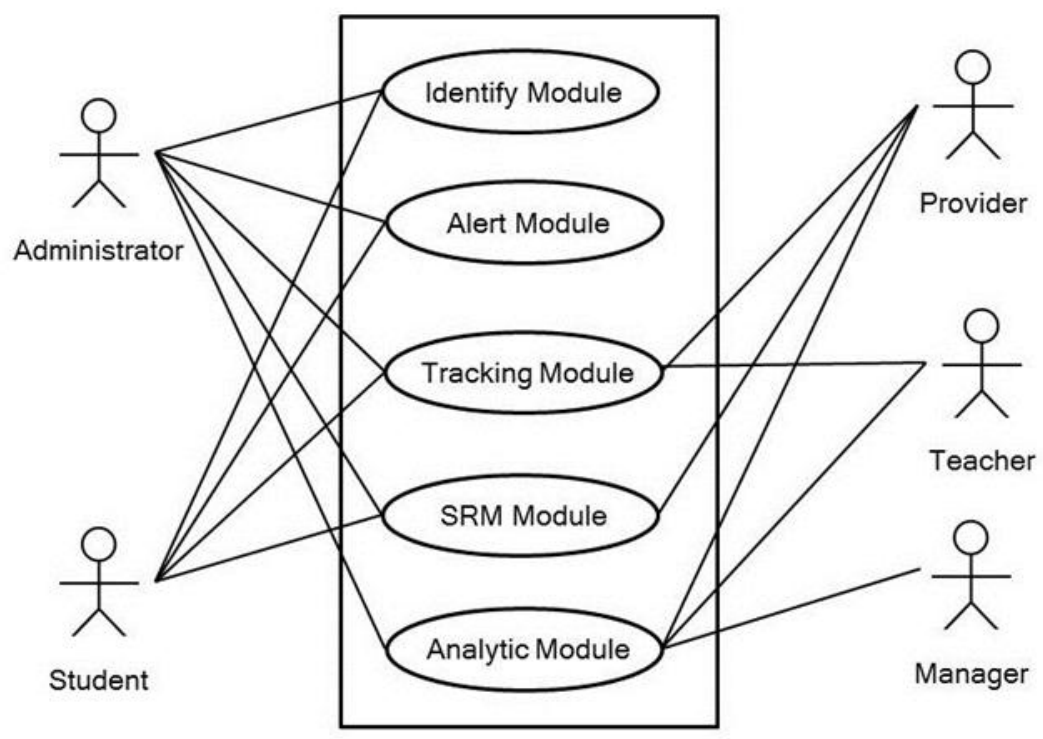

Fig. 2. The use case diagram of the SRMS using IoT to collect digital footprint of higher education institutions

Based on Fig. 2, the use case descriptions are as follows:

Table 1. Use Case Description

\begin{tabular}{|c|l|l|}
\hline Actor & \multicolumn{1}{c|}{ Module } & \multicolumn{1}{c|}{ Role } \\
\hline \multirow{3}{*}{ Administrator } & Identify Module & - manage data user for adding, updating \\
and deleting \\
\cline { 2 - 3 } & Alert Module & - checking and maintaining hardware, \\
\cline { 2 - 3 } & Tracking Module & \\
\hline
\end{tabular}




\begin{tabular}{|c|c|c|}
\hline & SRM Module & software and database of system \\
\hline & Analytic Module & - advice for using system \\
\hline \multirow{4}{*}{ Student } & Identify Module & - access services stations \\
\hline & Alert Module & - receive alert messages \\
\hline & Tracking Module & $\begin{array}{l}\text { - to be tracked by the system } \\
\text { - to be have tracking data collected }\end{array}$ \\
\hline & SRM Module & - receive SRM alert messages \\
\hline \multirow{3}{*}{ Provider } & Tracking Module & $\begin{array}{l}\text { - check and use tracking data for } \\
\text { planning and to manage services } \\
\text { stations }\end{array}$ \\
\hline & SRM Module & $\begin{array}{l}\text { - manage data SRM for adding, } \\
\text { updating and deleting from services } \\
\text { stations }\end{array}$ \\
\hline & Analytic Module & $\begin{array}{l}\text { check and use reports for planning } \\
\text { and to manage services stations }\end{array}$ \\
\hline \multirow{2}{*}{ Teacher } & Tracking Module & $\begin{array}{l}\text { - check and use tracking data for } \\
\text { planning and to manage students }\end{array}$ \\
\hline & Analytic Module & $\begin{array}{l}\text { - check and use reports for planning and } \\
\text { to manage students }\end{array}$ \\
\hline \multirow{2}{*}{ Manager } & Tracking Module & $\begin{array}{l}\text { - check and use tracking data for } \\
\text { planning and to manage HEIs }\end{array}$ \\
\hline & Analytic Module & $\begin{array}{l}\text { - check and use reports for planning and } \\
\text { to manage HEIs }\end{array}$ \\
\hline
\end{tabular}

- Phase 2: Overview of the SRMS using IoT to collect digital footprint of higher education institutions is shown in Fig 3.

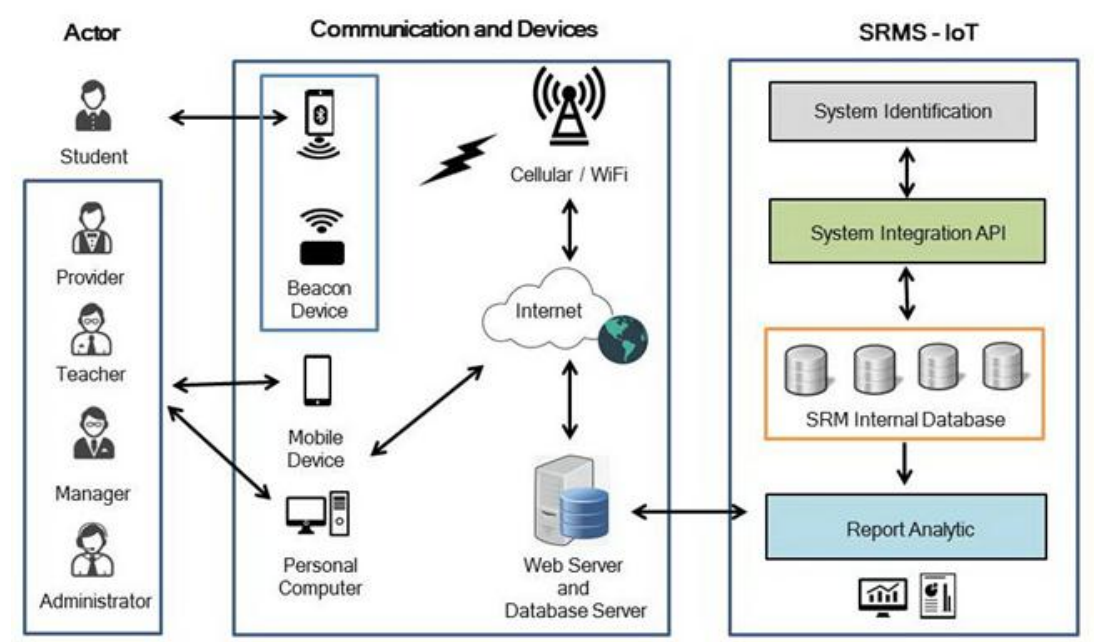

Fig. 3. Overview system of the SRMS using IoT to collect digital footprint of higher education institutions

Overview system of the SRMS using IoT to collect digital footprint of higher education institutions consists of three main parts as follows: 


\subsection{Actors}

Users of the system can be divided into five actors: students, providers, teachers, managers and administrators. Students can use the application on mobile devices. Providers and administrators prepare beacon devices at service stations for the support system for students access at the service stations. Providers, teachers, managers and administrators can use the application on mobile devices and personal computers.

\subsection{Communication and devices}

Communication and devices include beacon devices and receivers (mobile device) for service stations. Users can access from mobile devices or personal computers that are connected to the Internet signal (Cellular/Wi-Fi, 3G, 4G, and 5G). The system is built as a web application that is installed in the web server and database server.

\subsection{Student Relations Management Systems using Internet of Things (SRMS - IoT)}

The SRMS using IoT consists of modules that work together including the identification, alert, tracking, SRM and analytic modules. The SRM internal system is a database that supports four services stations: the library, academic services, student affairs and the first aid room.

- Phase 3: System architecture of the SRMS using IoT to collect digital footprint of higher education institutions is shown in Fig. 4. 


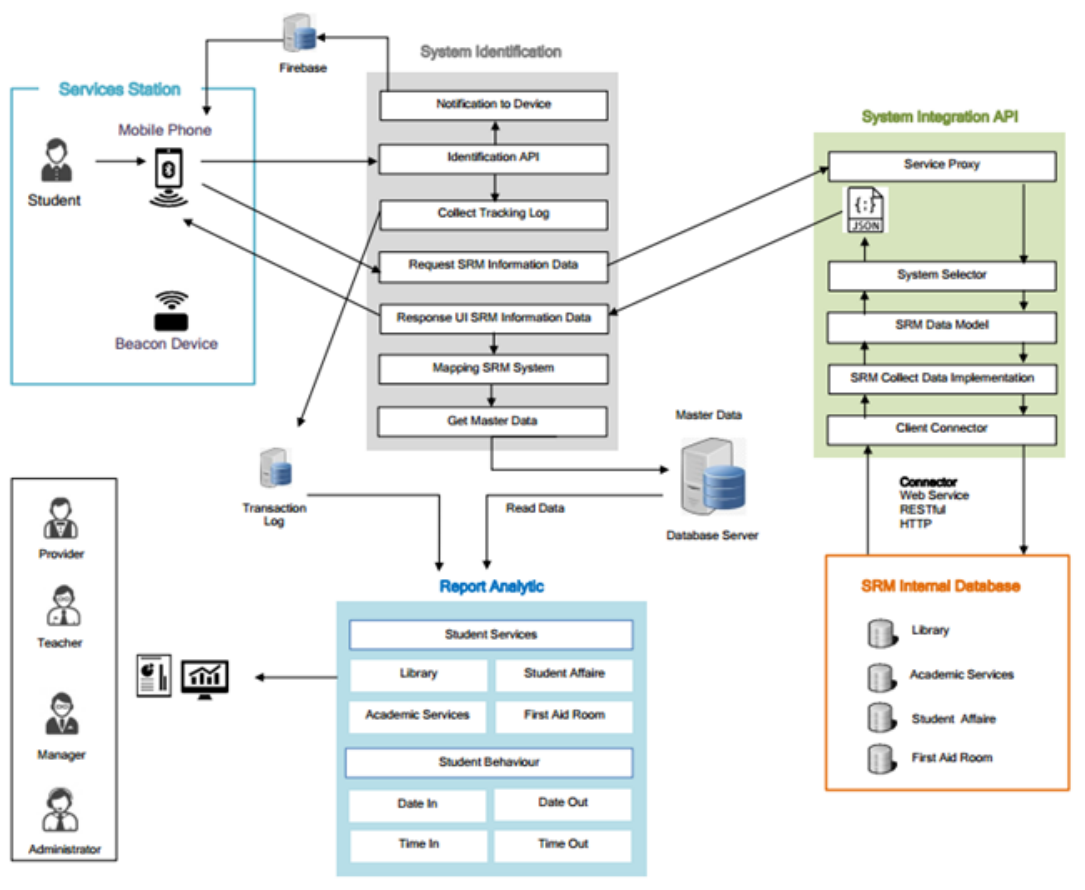

Fig. 4. System architecture of the SRMS using IoT to collect digital footprint of higher education institutions.

The system architecture of the SRMS using IoT to collect digital footprint of higher education institutions consists of six main parts as follows:

\section{1) Service Stations}

Service stations are areas that are set up as beacon devices for receiving signals to access the system. There are four services stations: the library, academic services, student affairs and the first aid room.

The system starts working when students access service stations with their mobile devices that have installed the SRMS-IoT system with the Bluetooth being turned on; then the beacon devices in the service stations automatically connect and send alert messages to the mobile devices.

\section{2) System identification}

System identification checks, identifies and connects data to others part of the system when students access the service stations. Students' mobile devices that receive a signal from a beacon device will start the identification section; this is divided into three parts that work together as follows:

Notification for students to acknowledge: The system will send data through the API, which is checked for identification. After that, it will send information to alert 
students using messages on their mobile devices for storing students' access to the databases.

To store students' access: The data will be sent via API, which is validated for identification. After that, the log data will be stored in the form of a tracking log to be prepared for further analysis.

Calling information that students have already used in the service stations: The system will request the SRM information. There will be further processed in the next part (System Integration API), which finds the student data from the previously accessed service stations. If the student data is discovered, the system will send an alert message to the student and connect to the main database to store for further analysis and reporting.

\section{3) System Integration API}

System Integration API retrieves information that the students have accessed previously in the service stations. The system sends a signal request for SRM information respectively to System Integration API consists of five parts:

- Services proxy

- System selector

- SRM data model

- SRM collect data implementation

- Client connector

The client connector using a web service to connect SRM internal system which include the library, academic services, student affairs and the first aid room. After that, SRM internal system will send data return to part that request SRM information by JSON will be used to support various data.

\section{4) SRM Internal System}

The SRM internal system collects data and links to four service stations: the library, academic services, student affairs and the first aid room. Details of the services are as follows:

Library: Book borrowing, book return, library activities, service fees;

Academic services: Academic calendar, registration schedule, grade submission schedule, adding - withdrawing courses and document fee rates;

Student affairs: News or activities, accident insurance, military waiver and scholarship news;

First aid room: Doctor/nurse schedule, health promotion activities

5) Report analytic

The report analytic analyse the received information from all systems and processes them for reporting purposes. It consists of two main parts:

Student services report: Student services reports will show the results of analyzing students' services data from four service stations: the library, academic services, 
student affairs and the first aid room. Information from the student services reports can be viewed instantly and change in real time.

Student behavior report: Student behavior reports will show the results of analyzing students' services data from four services station: the library, academic services, student affairs and the first aid room. The system will analyze data on the date of walk in, time of walk in, date of walk out, and time of walk out. Information in the Student behavior reports are able to process data, frequency and duration that students access service stations.

6) Web server and database server

The web server and database server consist of a server that provides the website of the SRMS using IoT to collect digital footprint of higher education institutions and a database management system to manage data of the transaction logs and master logs to be used in the system.

\subsection{Phase 4:}

Evaluation of the system architecture of the SRMS using IoT to collect digital footprint of higher education institutions is shown in Table 2.

Table 2. Evaluation of the system architecture of the SRMS using IoT to collect digital footprint of higher education institutions.

\begin{tabular}{|c|c|c|c|}
\hline List of Evaluation & $\bar{x}$ & S.D. & $\begin{array}{c}\text { Level of } \\
\text { appropriateness }\end{array}$ \\
\hline \multicolumn{4}{|c|}{ 1. Actor } \\
\hline 1.1 Student & 5.00 & 0.00 & very high \\
\hline 1.2 Provider & 5.00 & 0.00 & very high \\
\hline 1.3 Teacher & 5.00 & 0.00 & very high \\
\hline 1.4 Manager & 4.90 & 0.32 & very high \\
\hline 1.5 Administrator & 5.00 & 0.00 & very high \\
\hline \multicolumn{4}{|c|}{ 2. IoT Device } \\
\hline 2.1 Mobile Phone & 5.00 & 0.00 & very high \\
\hline 2.2 Beacon Device & 4.80 & 0.42 & very high \\
\hline \multicolumn{4}{|c|}{ 3. SRMS - IoT } \\
\hline 3.1 System Identification & 4.90 & 0.32 & very high \\
\hline 3.2 System Integration API & 4.70 & 0.67 & very high \\
\hline 3.3 SRM Internal System & 4.70 & 0.48 & very high \\
\hline 3.4 Alert Message & 4.50 & 0.53 & high \\
\hline 3.5 Report Analytic & 4.50 & 0.53 & high \\
\hline 4. Web Server and Database Server & 4.80 & 0.42 & very high \\
\hline Total & 4.83 & 0.33 & very high \\
\hline
\end{tabular}

According to Table 2, the overall result of the evaluation of the system architecture of the SRMS-IoT to collect digital footprint of higher education institutions was at a very high appropriate level $(\bar{x}=4.88, S . D .=0.30)$. Considering each item, most items 
were at a very high appropriate level, with the exception of SRMS-IoT for Alert Message and Report Analytic, which were at a high appropriate level.

The item evaluation results of the system architecture of the SRMS-IoT to collect digital footprint of higher education institutions were at very high appropriate levels, as follows:

- Actor

- IoT Device

- SRMS-IoT

- Web Server and Database Server

Considering each item, most items were at a very high appropriate level.

\section{Conclusion}

According to the evaluation results, the system architecture of the SRMS-IoT to collect digital footprint of higher education institutions had an overall appropriateness at a very high level. Considering each item, most items were at a very high appropriate level, except for SRM Internal System and Alert Message, which were at a high appropriate level, which showed that the experts had consistent opinions.

As shown in the overview, the SRMS using IoT to collect digital footprint of higher education institutions consisted of three main parts:

- Actor

- Communication and Devices

- The SRMS-IoT

This is in accordance with Phumeechanya [17], who designed the mobile web application with an online map service for storing student teaching and internship information. This system architecture consisted of:

- User

- Communication and Device

- Mobile Web Application.

As shown, the system architecture of the SRMS - IoT to collect digital footprint of higher education institutions consists of six main parts:

- Services Station

- System Identification

- System Integration API

- SRM Internal System

- Report Analytic

- Web Server and Database Server.

Part 1: A service station is an area that sets up a beacon device to receive signals to access the system when students access fours service stations: the library, academic 
services, student affairs and the first aid room. This is in accordance with Akpan [2], who stated that services provided to students are suitable for a variety of activities including admission, registration, orientation, and screening of new and final year students, library services, guidance and counselling services, health services, communication processes and allocation of materials.

Part 2: System identification checks, identifies and connects data to others parts of the system when students access a service station. This is in accordance with Alqahtani and Al-Sakran [9] who demonstrated that identification perception layers consist of RFID components (RFID embedded wristbands, RFID reader) set in school areas and on the school bus, GPS and other sensors used to track students and school bus movements.

Part 3: The System Integration API retrieves information that students accessed previously in service stations. This is in accordance with Saraubon, Nilsook and Wannapiroon [15], who showed that communication between clients' devices and systems consists of data transmission and data retrieval. Further, JSON will be used to support various information such as quizzes, personal data, messages, explanations, etc.

Part 4: The SRM Internal System collects data and links to four service stations: the library, academic services, student affairs and the first aid room. This is in accordance with Phumeechanya [17] who demonstrated that the system will be linked to the MySQL database developed by PHP and SQL. Part of the database can added, deleted or edited. The main database of the system includes a table of school data, students' data, teachers' data and teaching and internship data.

Part 5: Report Analytic receives information from all systems and process for reporting purposes. This is in accordance with Fan et al. [19] who studied data collection for analyzing student behavior such as information on borrowing books, consumer information (cafeterias, supermarkets, dormitories, etc.), and access to information, library information and ranking information on students' achievements. The results will support the management of higher education institutions and the daily life of students.

Part 6: The web server and database server consist of a server that provides the website of the SRMS using the IoT to collect digital footprint of higher education institutions. This is in accordance with Chatwattana and Nilsook [20], who designed a database system using the MySQL program to manage systems that include exam scores, exam forms, attendance history use systems, subjects, content, etc. The database system supports data for students, lectures and administrators.

\section{$7 \quad$ Acknowledgement}

This work is partly supported by Suan Dusit University (SDU), Thailand, King Mongkut's University of Technology North Bangkok (KMUTNB), Thailand and Murdoch University in Perth, Western Australia. 


\section{$8 \quad$ References}

[1] K. Roger and H. Enrique Danja, Student Affairs and Services in Higher Education: Global Foundations, Issues and Best Practices. International Association of Student Affairs and Services (IASAS). In Cooperation with: The United Nations Educational, Scientific and Cultural Organisation (UNESCO), 2009.

[2] U. Chineze M., A. Stephen C., N. Lekia, M. J. N. (2016).Students Personnel Services in Higher Education. Edition: 1st Edition, Chapter: Four, Publisher: University of Port Harcourt Press, Port Harcourt, Nigeria

[3] R. Wang, F. Chen, Z. Chen, T. Li, G. Harari, S. Tignor, X. Zhou, D. Ben-Zeev and A. T. Campbell, "Student Life: Assessing Mental Health, Academic Performance and Behavioral Trends of College Students using Smartphones," in Ubicomp '14, September 13 - 17, 2014, Seattle, WA, USA. https://doi.org/10.1145/2632048.2632054

[4] R. Wang, G. Harariy, P. Hao, X. Zhou, and A. T. Campbell, "Smart GPA: How Smartphones Can Assess and Predict Academic Performance of College Students," in UbiComp '15, September 07-11, 2015, Osaka, Japan.

[5] S. Heydar Mirfakhradini, R. Ebrahimizade Pezeshki, M. Khoshghamat and F. Famil Samavati, "A Comprehensive Model for Student Relationship Management Based on Interpretative Structural Modelling: The Case of Yazd University," International Journal of Scientific Management and Development, vol.2 (7), pp. 242-251, July 2014.

[6] J. Pongpilasarn and S. Tangwannawit, "Development of a Graduate Level Student Relationship Management Model," in NCCIT2014. The Tenth National Conference on Computing and Information Technology, pp. $988-993$.

[7] D. J. Burnett, Innovation in Student Services: Best Practice and Process Innovation Models and Trends. 2010.

[8] S. Li, L. D. Xu and S. Zhao, The Internet of Things: A Survey. New York: Springer, 2015.

[9] H. Alqahtani and H. Al-Sakran, "Towards Safe Commuting: Using Internet of Things for Building Smart Student Tracking System," International Journal of Advanced Research in Computer Science and Software Engineering, vol. 6 (11), pp. 32 - 42,s November 2016.

[10] K. McDonald and I. Glover, "Exploring the transformative potential of Bluetooth beacons in higher education," Research in Learning Technology, 24 (1), p., 2016. https://doi.org/ $\underline{10.3402 / \text { rlt.v24.32166 }}$

[11] R. Lambiotte and M. Kosinski, "Tracking the Digital Footprints of Personality," in Proceedings of the IEEE, vol. 102, No. 12, December 2014.

[12] J. Hinds and A. M. Joinson. (2018). What demographic attributes do our digital footprints reveal? A systematic review. PLoS ONE 13(11): e0207112. https://doi.org/10.1371/journ al.pone.0207112

[13] N. Songsom, P. Nilsook and P. Wannapiroon, "The Synthesis of the Student Relationship Management System using the Internet of Things to collect the Digital Footprint for Higher Education Institutions," International Journal of Online and Biomedical Engineering, vol. 15, no. 6, pp. 99 - 112, 2019. https://doi.org/10.3991/ijoe.v15i06.10173

[14] Microsoft (2009), Microsoft @ Application Architecture Guide, 2nd Edition.

[15] K. Saraubon, P. Nilsook and P. Wannapiroon, "System Design of Mobile Augmented Book," International Journal of Interactive Mobile Technologies,vol. 10 (1), pp. 52 - 59, 2016. https://doi.org/10.3991/ijim.v10i1.5276

[16] R. Laoha, P. Wannapiroon and P. Nilsook, "The System Architecture of Digital Activity Portfolio via Internet of Things for Digital University," International Journal of Advanced and Applied Sciences, vol.6 (2), pp. 81-86, 2019. 
[17] N. Phumeechanya, "Development of Mobile Web Application with Online Map Services for Storing Student Teaching and Internship Informational," Journal of Industrial Education, vol. 17 (1), pp. 175 - 183, January - April, 2018.

[18] H. A. Kadir, M. H. A. Wahab, Z. Tukiran, M. R. M. Tomari and M. N. H. Mohd, "Fusion of Radio Frequency Identification (RFID) and Fingerprint in Boarding School Monitoring System (BoSs)," in Sustainable Radio Frequency Identification Solutions, C. Turcu, Ed., 2010, pp.74-9. https://doi.org/10.5772/8012

[19] S. Fan, P. Li, T. Liu and Y. Chen, "Population Behavior Analysis of Chinese University Students via Digital Campus Cards," in IEEE 15th International Conference on Data Mining Workshop, pp. 72-77, 2015. https://doi.org/10.1109/icdmw.2015.45

[20] P. Chatwattana and P. Nilsook, "A Web-based Learning System using Project-based Learning and Imagineering. International Journal of Emerging Technologies in Learning, vol.12 (5), pp. 4 - 22, 2017. https://doi.org/10.3991/ijet.v12i05.6344

\section{Authors}

Nualsri Songsom is a Lecturer of Business Computer, Faculty of Management, Suan Dusit University, Thailand. Her research interests focus on Student Relationship Management, Internet of Things, and Digital Footprint.

(e-Mail : nuasri_son@dusit.ac.th)

Prachyanun Nilsook is an Associate Professor at the Division of Information and Communication Technology for Education, King Mongkut's University of Technology North Bangkok (KMUTNB), Thailand. He currently works in the field of ICT for Education and Vocational Education Technology Research Centre. He is a member of Professional Societies in the Association for Educational Technology of Thailand (AETT) (e-Mail: prachyanunn@kmutnb.ac.th)

Panita Wannapiroon is an Associate Professor at the Division of Information and Communication Technology for Education, and the Director of Innovation and Technology Management Research Centre (ITMRC), Science and Technology Research Institute (STRI), King Mongkut's University of Technology North Bangkok (KMUTNB),Thailand. Presently, she works in the field of ICT in Education. (e-Mail: panitaw@kmutnb.ac.th)

Lance Chun Che Fung is an Emeritus Professor in the College of Science, Health, Engineering and Education at Murdoch University in Western Australia. He is also the current chapter chair IEEE New Initiatives Committee (NIC), chair for IEEE Asia Pacific Region Educational Activities Committee (R10 EAC) and chair for IEEE Systems, Man and Cybernetic (SMC) Society (WA Chapter). His research interest is in the Development and Applications of Innovative Intelligent Technologies and Advanced Techniques to solve Practical Problems. (e-Mail: L.Fung@ murdoch.edu.au)

Kok Wai Wong is an Associate Professor with the Discipline of Information Technology, Mathematics and Statistics at the College of Science, Health, Engineering and Education at Murdoch University in Western Australia. He is the current Vice President (Membership) for The Asia Pacific Neural Network Society (APNNS). He is a Senior Member of Institute of Electrical and Electronics Engineers (IEEE), a Senior member of Australia Computer Society (ACS), and Certified Professional of 
ACS. He is also the current chapter chair for IEEE Computer Intelligence Society (WA Chapter). He is involved in the editorial boards for a number of international journals and in many international conference organising committees. His current research interests include Intelligent Data Mining, Artificial Intelligence and Machine Learning, and Game and Virtual Reality Technology.(e-Mail :K.Wong@murdoch.edu. au)

Article submitted 2019-06-19. Resubmitted 2019-08-09. Final acceptance 2019-08-12. Final version published as submitted by the authors. 